\title{
Feminicídio:
}

\section{Feminismo e Direito Penal Simbólico}

\section{Tanise Zago Thomasi}

Doutora em Direito pelo Centro Universitário de Brasília Uniceub. Mestre em Direito pela Universidade de Caxias do Sul - UCS. Professora universitária na Universidade Tiradentes - Unit. tanisethomasi@gmail.com

\section{Luanny Corrêa Fontes}

Graduada em Direito pela Universidade Tiradentes - Unit. luannyfontes@gmail.com

\section{Resumo}

0 objetivo do trabalho é verificar se o feminicídio, modalidade do crime homicídio inserida na legislação penal pela Lei n. 13.104/2015, constitui uma nova incidência do chamado direito penal simbólico, estudando a trajetória traçada pelo feminismo no direito brasileiro e sua atuação contra a violência em razão de gênero, bem como as características e funções do direito penal. A pesquisa demonstra que as circunstâncias e os motivos da inclusão da norma no ordenamento jurídico têm berço no movimento feminista, revelando sua afinidade com as causas sociais responsáveis por sua instituição e a prioridade que deposita na função simbólica da lei penal. Emprega-se, para tal, o método dedutivo, analisando concepções depreendidas de estudos já anteriormente efetuados.

Palavras-chave: Feminicídio. Feminismo. Direito penal simbólico. 


\title{
FEMINICIDE: feminism and symbolic criminal law
}

\begin{abstract}
This paper's goal is to verify if the feminicide, a form of the crime of homicide introduced into the criminal legislation through the Law 13.104/2015, constitutes a new incidence of the so called symbolic criminal law, studying the path trailed by feminism in Brazilian law and its activity against gender-motivated violence as well as the characteristcs and functions of criminal law. The reserach concludes that the circumstances and motivation behind the norm are a consequence of the feminist movement, revealing its affinity with the social causes responsible for its introduction and the priority it places on the symbolic function of criminal law. The method employed is deductive, verifying and analyzing concepts gathered from previous studies.
\end{abstract}

Keywords: Feminicide. Feminism. Symbolic criminal law.

Recebido em: 14/10/2016

Revisões requeridas em: 16/10/2017

Aceito em: 21/11/2017

\section{Sumário}

1 Introdução. 2 Direito penal simbólico. 2.1 Ciências de repressão do crime. 2.2 Função simbólica do direito penal. 3 Feminismo e direito. 4 Feminicídio. 4.1 Feminicídio tipificado. 5 Função simbólica do feminicídio. 5 Considerações finais. 6 Referências. 


\section{INTRODUÇÃO}

Tem-se tornado crescente alvo de críticas entre a doutrina o chamado direito penal simbólico, isto é, a tendência da divisão legislativa do poder estatal de elaborar e aprovar leis no âmbito do direito penal com fins simbólicos, buscando, primeiramente, instaurar uma ilusão de tranquilidade na sociedade perante a atual difusão do medo e da indignação diante do crime, à medida que o real fim explorado nessa área do direito, o controle do delito, passa a ser negligenciado.

Paralelamente a esse contexto, foi promulgada a lei n. 13.104, em 8 de março de 2015, Dia Internacional na Mulher, que inclui o feminicídio no rol da lei dos crimes hediondos ao categorizá-lo como modalidade qualificada do crime de homicídio. Críticos do direito penal simbólico apontam esse evento como mais uma aplicação prioritária da função simbólica da lei penal, sem preocupação com sua efetividade no combate ao crime, cuja definição consta de seu tipo.

Em virtude disso, o presente artigo tem como objetivo debater a recente qualidade hedionda do feminicídio como instrumento de análise e sua eficiência na repressão do crime e consequente proteção do bem jurídico que tutela. Assim, indaga-se se o enrijecimento punitivo do Estado, no tocante à pratica do feminicídio, trata-se de mera instância do direito penal simbólico. Num primeiro momento, a autora supõe que a resposta ao problema discutido seja positiva, uma vez que, a exemplo de vários outros tipos penais inseridos na legislação brasileira em resposta ao clamor social, comprova-se que a repressão do crime tem foco subsidiário à força simbólica exercida.

Para elucidar essa questão, utilizou-se do método dedutivo, posto que a hipótese em questão será verificada e analisada a partir das concepções depreendidas de estudos já efetuados. A abordagem 
também é qualitativa, uma vez que a pesquisa foi realizada por meio de leitura, análise e interpretação. A técnica de pesquisa aplicada foi a bibliográfica.

A rigorosidade na legislação penal e sua função simbólica é matéria por que se interessou a autora enquanto cursava a disciplina de Criminologia, oportunidade em que presenciou diversos debates acerca da disseminação desse instrumento na esfera legislativa do poder estatal.

Ademais, o trabalho proposto poderá contribuir para os estudos acerca do direito penal simbólico no sistema legal brasileiro, além de promover um olhar sobre a necessária intervenção do feminismo na área jurídica.

\section{DIREITO PENAL SIMBÓLICO}

O direito penal é um conjunto de normas que define os delitos e as sanções que lhes correspondem, aliado do direito do Estado de punir, o chamado jus puniendi, relativo a sua exclusiva faculdade de impor sanção criminal diante da prática do delito (PRADO, 2010, p. 65). Estão atribuídos a essa ciência princípios consequentes do garantismo da vigente Constituição Federal, posto que sua atuação consiste na determinação e imposição de restrições a direitos individuais.

Sua aplicação prática apresenta, porém, desvios dos freios que são impostos ao legislador no momento de categorizar condutas delituosas e suas respectivas penas. Neste tópico, debate-se a hipervalorização do caráter simbólico do direito penal, geralmente ligada a fins políticos, analisando sua ocorrência progressivamente comum nesse setor do ordenamento jurídico.

\subsection{Ciências de Repressão do Crime}

O teórico Franz Von Liszt vislumbra o alinhamento entre três ciências que atuam em união com a finalidade de repreender a incidência criminal, sendo elas o direito penal, a política criminal e a criminologia (1899, p. 35). 
O direito penal tem natureza jurídica, sendo, dessa forma, a ciência sistemática e estritamente técnica, tomando por objeto geral a conduta humana e, por objeto especial, a responsabilidade dos que violam as normas sancionadas pela lei penal. Esse ramo também é conhecido como dogmática penal, uma vez que "parte de normas positivas, consideradas como dogma, para a solução dos problemas” (PRADO, 2010, p. 66). Por sua vez, a política criminal aprecia o direito existente, correlacionando-o com o fim do direito penal, isto é, a repressão do crime, indicando, dentre os meios disponíveis, os mais adequados para a consecução desse objetivo. Finalmente, a criminologia, ora apelidada de "ciência do crime", preocupa-se com as causas e natureza do crime a partir do pensamento claro e da observação sistemática (LISZT, 1899, p. 34-36).

O direito penal é regido, dentre outros, pelo princípio da intervenção mínima do direito penal, que se divide em dois aspectos. $\mathrm{O}$ primeiro deles é a fragmentariedade, pela qual se estabelece que o direito penal é pontual no conjunto total do ordenamento jurídico, somente incidindo em casos isolados, em razão de presumido interesse social sobre eles. "O Direito Penal limita-se a castigar as ações mais graves praticadas contra os bens jurídicos mais importantes, decorrendo daí o seu caráter fragmentário” (BITENCOURT, 2012, p. 26).

Nisso, aliás, consiste a principal proteção política do cidadão em face do poder punitivo estatal, qual seja, a de que somente poderá ter invadida sua esfera de liberdade, se realizar uma conduta descrita em um daqueles raros pontos onde a lei definiu a existência de uma infração penal (CAPEZ, 2011, p. 36).

Aliada à fragmentariedade da intervenção mínima está a subsidiariedade, defendendo a incidência do ramo penal de forma acessória, ou seja, somente quando os demais campos do Direito, os controles formais e sociais, tenham perdido a eficácia e não sejam capazes de exercer tal tutela (CAPEZ, 2011, p. 39). Ela consagra o direito penal como ultima ratio, o 
último dos recursos legais a ser utilizado na repressão de lides, exigindo do legislador que a norma penal somente seja imposta quando se esgotem os demais meios por ele vislumbrados. "Não basta, portanto, haver provado a idoneidade da resposta penal; requer-se, também, demonstrar que essa não é substituível por outros modos de intervenção de menor custo social” (BARATTA, 1987).

É de suma importância a feição de ultima ratio em se apresenta a lei penal, particularmente porque a mínima intervenção é o único modelo penal compatível com um Estado Democrático de Direito, fulcrado em direitos e garantias; isso porque o "direito penal é de fato o terreno sob o qual, da maneira mais emblemática, se manifestam os limites da democracia política, entendida como o poder ou vontade do povo e, portanto, da maioria” (FERRAJOLI, 2002, p. 31). O direito penal mínimo é, desse modo, consequência de uma legislação penal garantista, que, por sua vez, visando à redução do custo social e individual da ingerência penal, decorre do princípio constitucional da dignidade humana, máxima fundamental da Lei Maior.

Tendo isso em vista, a política criminal surge como um instrumento protetor dos princípios norteadores do direito penal. É seu objetivo apurar tanto os resultados do desenvolvimento histórico da legislação penal de um país, quanto as reformas que nela devem ser introduzidas (LISZT, 1899, p. 36). Serve, pois, como um filtro entre os problemas sociais que anseiam pela tutela penal e a legislação penal vigente, bem como analisando o arcabouço jurídico e a realidade social para concluir qual é o método mais efetivo de se aplicar tais normas.

A política criminal objetiva, primordialmente, a análise crítica (metajurídica) do direito positivo, no sentido de bem ajustá-lo aos ideais jurídicos-penais e de justiça. Está intimamente ligada à dogmática, visto que na interpretação e aplicação da lei penal interferem critérios de política-criminal (PRADO, 2010, p. 66-67). 
A política criminal, portanto, corrobora com o direito penal mínimo, afastando, quando bem-empregada, da esfera penal os conflitos que não lhe pertencem.

Nota-se, destarte, que a estrutura formulada por Liszt expõe de forma objetiva o mecanismo da repressão estatal do crime, sendo interessante por afastar do direito penal preocupações que naturalmente não deveriam recair sobre seu estudo, deixando para outras esferas análises que se afastem do método técnico-jurídico e do estudo sistêmico das leis penais. Ela também consagra princípios preciosos ao direito penal nacional, resguardando sua função como ultima ratio em meio ao ordenamento jurídico e, portanto, o caráter do direito penal no Brasil.

\subsection{Função Simbólica do Direito Penal}

Embora o direito penal possua um arcabouço principiológico sintonizado com o garantismo constitucional, a realidade da legislação penal nacional se distancia do ideal de resposta ao crime em diversos tópicos. Dentro do contexto do presente trabalho, comenta-se sobre o direito penal simbólico.

A missão ou a função do direito penal está atrelada aos seus objetivos e metas. Nesse sentido, destacam-se as consequências queridas ou procuradas oficialmente pelo sistema, enquanto as consequências (funções efetivas) não desejadas (oficialmente e ostensivamente) se tornam a realidade desse sistema (GOMES, 2004, p. 20). As funções tratam, portanto, dos produtos observáveis no plano real do direito penal aplicado.

A função legítima do direito penal, também chamada de instrumental, é o papel que essa ciência deve cumprir na sociedade: "servir de instrumento para a tutela (fragmentária e subsidiária) dos bens jurídicos 
mais relevantes (vida, integridade física, etc.) e mesmo assim contra os ataques mais intoleráveis (contra as ofensas que efetivamente perturbam a convivência social)" (GOMES, 2004, p. 22).

Outra função, contudo, representando um desempenho deturpado da ciência, é observada na realidade penal - a função simbólica.

Sustenta-se que a função simbólica é aquela pela qual não se objetiva, através do instrumental punitivo do Estado, a resolução efetiva de conflitos de interesses sociais. O objetivo da pena e do Direito Penal para a visão simbólica é apenas a produção na opinião pública de uma impressão de tranqüilidade gerada por um legislador diligente e supostamente consciente dos problemas gerados pela criminalidade (ANJOS, 2007).

A anterior menção ao direito penal simbólico é, portanto, a superposição da função simbólica sobre a função instrumental. Dentre as motivações consta a edição de leis na esfera criminal, invertendo os valores que norteiam a elaboração dessas normas. Há discordância com a principiologia do direito penal: para atingir seu objetivo (ou seja, produzir uma impressão de diligência legislativa e judicial no combate ao crime), ela deve aumentar a incidência do direito penal, rompendo com o princípio da intervenção mínima, e tornando as penas mais duras. A função simbólica trabalha o impacto moral de uma estrutura penal endurecida e menos garantista, manipulando o sentimento social para disseminar uma sensação de satisfação com a atuação estatal. Nesse sentido, cabe examinar a lição de Bourdieu sobre símbolos e integração social:

Os símbolos são os instrumentos por excelência da "integração social": enquanto os instrumentos de conhecimento e de comunicação [...], eles tornam possível o consensus acerca do sentido do mundo social que contribui fundamentalmente para a reprodução da ordem social: a integração “lógica é a condição da integração moral” (1989, p. 10). 
A definição do termo originada no uso do poder político no direito penal, usa a ilusão de um sistema que ajuda a "limpar" a sociedade de suas mazelas para conter o ultraje popular, beneficiando aqueles investidos de autoridade pelas esferas do poder do Estado. Trata-se do uso do direito penal com fins políticos que ultrapassa o objetivo de efetiva tutela jurídica do bem que a norma penal supostamente tutela.

Esse fenômeno também é oriundo, de forma subsidiária, da atuação midiática na esfera penal do ordenamento jurídico. Quando a mídia manipula a notícia conforme as características preestabelecidas de um ou mais receptores (KERSTENETZKY, 2012), ela age como formadora de opinião.

O uso desvirtuado do Direito penal vem se acentuando nos últimos anos. A mídia retrata a violência como um "produto espetacular" e mercadeja sua representação. A criminalidade (e a persecução penal), assim, não somente possui valor para uso político (e, especialmente, para uso “do" político), senão que é também objeto de autênticos melodramas cotidianos que são comercializados com textos e ilustrações nos meios de comunicação. São mercadorias da indústria cultural de massa, gerando, para se falar de efeitos já aparentes, a sua banalização e a da violência (GOMES; BIANCHINI, 2007 apud KERSTENETZKY, 2012).

Resulta tal processo numa opinião pública deliberadamente viciada, na qual há incremento do medo, do alarme social, a ponto de desfazer os limites existentes entre o distante e o local (GOMES, 2007). Fala-se em premeditação da corrupção da opinião pública porque as "transgressões às normas são particularmente selecionadas para o noticiário se nelas puderem ser misturados julgamentos morais, quer dizer, se elas puderem dar motivo para que pessoas sejam valorizadas ou desrespeitadas" (CHAVES JUNIOR, 2011).

Ao tratar do movimento de expansão do direito penal, Bueno descreve o mesmo fenômeno observado no direito penal simbólico: 
O movimento de expansão do direito penal surge no contexto atual de generalização social do medo ante o delito e da demanda por mais proteção, estimuladas pelos meios de comunicação social que agem para formar uma opinião pública sobre determinado problema social, pré-definindo os contornos relevantes desse problema e as estratégias para o seu combate $(2011$, p. 86$)$.

Conclui-se que o direito penal empregado em razão de sua função simbólica, tem como produto a aplicação penal mais frequente no mundo jurídico, violando, portanto, o princípio da fragmentariedade; isso porque a função simbólica somente é eficaz (e, portanto, útil) quando ela consegue ser observada. Dessa forma, a pena tem de ser mais comum e mais severa.

Recordando a política criminal, considerando que ela, ao indicar as modificações a serem feitas no ordenamento penal, abrange "o conjunto de procedimentos pelos quais o corpo social organiza as respostas ao fenômeno criminal (DELMAS-MARTY, 2004, p. 5). Pode-se afirmar que certo instituto de direito penal tem caráter meramente simbólico, quando não tem preâmbulo na ciência da política criminal, isto é, quando não é fruto de observação ordenada da ciência criminal sobre o objeto que tutela.

Convém ressaltar que a função simbólica faz parte do direito penal, uma vez que ela é efeito do caráter coercitivo do direito penal. O problema encontra-se, contudo, na utilização do direito penal pelo Poder Político para cumprir apenas ou prioritariamente essa função, iludindo todos os seus destinatários com promessas irrealizáveis (GOMES, 2004, p. 23).

O problema encontra-se, enfim, na transformação do direito penal em mero símbolo, uma vez que o direito penal simbólico "não teria função instrumental - ou seja, não existiria para ser efetivo -, mas teria função meramente política, através da criação de imagens ou de símbolos que atuariam na psicologia do povo, produzindo determinados efeitos úteis" 
(SANTOS, 2002, p. 56). Trata-se, pois, de uma desvirtuação da disciplina, afastando-a de seus pilares e trocando a hierarquia de seus objetivos, valorizando os colaterais em detrimento dos primordiais.

\section{FEMINISMO E DIREITO}

Feminismo é um movimento pelo qual se busca a melhoria da condição de vida das mulheres, objetivando eliminar a diferença entre os status dos gêneros e conceder às mulheres as mesmas garantias que já eram conferidas aos homens (BUENO, 2011, p. 35). Assim sendo, o movimento procura atingir todas as esferas da experiência humana de modo a erradicar desvantagens que ainda se imponham a mulheres em sua realidade social.

Naturalmente, ele é uma resposta à subjugação feminina pelo homem, consequência da institucionalização de uma discrepância entre os gêneros pela evolução histórica ocidental pela qual o homem foi tomado como figura central na sociedade, reservando à mulher um papel secundário, quase invisível. A essa disparidade de gênero social e culturalmente instituída, pela qual a figura masculina detém o poder político, econômico e sexual (NETTO; BORGES, 2013, p. 320), dá-se o nome de patriarcado. Assim,

Deve ficar claro, porém, que estas relações entre os gêneros não precisam ser necessariamente desiguais. A desigualdade surge da relação de dominação-exploração da mulher pelo homem que, segundo Safiotti (2004, p. 118) são duas faces da mesma moeda (NETTO; BORGES, 2013, p. 320).

Desse modo, a luta do feminismo, apesar de ter tomado diferentes perspectivas no seu decorrer, sempre se instaurou, de uma forma ou de outra, contra essa hierarquia social androcêntrica que presume o homem como o padrão, como o superior, e a mulher como a exceção, o inferior. 
Unindo a onipresença do feminismo e a diversificação de seus aspectos militantes, além da aplicação pré-feminista do princípio historicamente cultivado da igualdade, o movimento sobreveio, também, sobre o direito; isso porque a equidade entre membros da sociedade, por séculos, não incluiu a mulher em seu conceito. De fato, quando a constitucionalidade trouxe direitos e garantias sociais mais sensíveis (com o multiculturalismo dos povos ocidentais), a igualdade finalmente transcendeu a diferença de gênero. Ainda que meramente teórico, o "princípio da igualdade finalmente chegava no mundo jurídico” (RAPOSO, 2004 apud BUENO, 2011, p. 57).

A equidade assume aspecto material quando os Estados de direito sofrem uma limitação sistematizada de sua soberania pelo movimento universal em prol dos direitos humanos (BUENO, 2011, p. 61). Assim, é apenas quando os direitos passam a ser percebidos pelos indivíduos como seus, em razão de uma tendência coletiva, e não como uma concessão que o Estado lhes garante, é que eles conseguem ultrapassar os limites da teoria e adentrar a realidade.

Mesmo, todavia, com a ratificação social de direitos que anteriormente eram puramente formais, ainda enfrenta-se o patriarcado na sociedade atual, e não se trata de meros resquícios de uma hierarquia social outrora existente. $\mathrm{O}$ patriarcado é reafirmado pelas instituições sociais basilares, responsáveis pela construção da moral:

A religião, a família, os mecanismos de comunicação de massa, a política, o direito, têm como paradigma essencial o masculino ocidental. Desta forma, a mulher é considerada e visibilizada dentro de todas essas instâncias de poder somente como o outro sexo. Causa perplexidade pensar que a mulher não existe ou não é enxergada, para essas instituições, sob outra ótica que não seja a machista e patriarcal, e que a tentativa de outra visão impossibilita o reconhecimento da mulher como sujeito de direitos (NETTO; BORGES, 2013, p. 328). 
É precisamente essa disseminação de uma visão androcêntrica que leva à aceitação coletiva da subjugação da mulher em dias atuais, que se traduz no cotidiano como formas de violência em razão de gênero e discriminação, dentre outras realidades culturalmente impostas à figura feminina.

É diante desse modelo moral que se deduz que a mera obediência às regras sociais conduz à violência de gênero, constituindo mais um forte elemento para corroborar a afirmação de que a violência de gênero é estrutural (BIJOS, 2004, p. 119).

A sociedade patriarcal confere ao homem o domínio do lar, sendo a ele resguardada a autoridade da área de convivência familiar, outrora garantida pela legislação. A alteração legal da percepção masculina, em que resultou a disseminação da igualdade de direitos, ainda não é percebida fora do campo jurídico formal:

Os homens reinam soberanos no espaço privado, como detentores do monopólio do uso "legítimo" da força física. Com efeito, o domicílio constitui um lugar extremamente violento para mulheres e crianças de ambos os sexos, mas especialmente para as meninas. Desta sorte, as quatro paredes de uma casa guardam os segredos de sevícias, humilhações e atos libidinosos/estupros à posição subalterna da mulher e da criança diante do homem e da ampla legitimação social dessa supremacia masculina (BIJOS, 2004, p. 120).

Essa segurança da afirmação masculina sobre a mulher não permanece, contudo, dentro do espaço privado. Sendo um postulado cultural decorrente do paradigma biológico da discriminação em razão de gênero, ela se repete, ainda que com menos liberdades do que aquelas consentidas ao homem no seio familiar, na vida em sociedade.

Em razão disso, o movimento feminista empenhou-se por defender intervenções sobretudo no âmbito do Direito Penal sexual e da violência doméstica, que defendiam claras discriminações positivas em favor das mulheres (BUENO, 2011, p. 87). Essa intervenção é defendida pelo poder 
simbólico da lei penal, uma vez que "a criminalização de uma conduta acarreta a percepção social de sua gravidade, alçando esse comportamento à posição superior na hierarquia das condutas cuja reprovabilidade demanda uma reação mais severa do Estado" (BUENO, 2011, p. 87). Entende-se, portanto, que a introdução de símbolos no direito penal integra manifestadamente a pauta feminista, encontrando apoio e movimento e elaboração de leis penais essencialmente simbólicas.

\section{FEMINICÍDIO}

O termo feminicídio é atribuído a Diana Russel, que é creditada com o uso da expressão pela primeira vez durante um depoimento feito em 1976. Foi posteriormente definido por sua autora, em colaboração com outras pesquisadoras, como um "continuum de violência contra as mulheres” (GEBRIM; BORGES, 2014, p. 62).

O feminicídio constitui a manifestação mais extremada da violência machista fruto das relações desiguais de poder entre os gêneros. Ao longo da História, nos mais distintos contextos socioculturais, mulheres e meninas são assassinadas pelo tão-só fato de serem mulheres. $\mathrm{O}$ fenômeno forma parte de um contínuo de violência de gênero expressada em estupros, torturas, mutilações genitais, infanticídios, violência sexual nos conflitos armados, exploração e escravidão sexual, incesto e abuso sexual dentro e fora da família (BIANCHINI; GOMES., 2015).

Embora feminicídio e feminicício tenham sido utilizados em países da América Latina como sinônimos, mantendo o sentido cunhado por Russel, Marcela Lagarde disseminou a utilização do termo feminicídio com a intenção política feminista de destacar tanto a violência contra as mulheres quanto a impunidade de seus agressores, transformando o termo em si próprio num comentário social. Segundo sua definição, o feminicídio não é apenas uma violência exercida em razão de gênero, por homens contra mulheres, mas "por homens em posição de supremacia 
social, sexual, jurídica, econômica, política, ideológica e de todo tipo, sobre mulheres em condições de desigualdade, de subordinação, de exploração ou de opressão, e com a particularidade da exclusão" (GEBRIM; BORGES, 2014, p. 62).

É necessário enfatizar que o feminicídio assume uma característica universal. Dessa forma, não poderia ser categorizado como um caso pontual ocorrido em relação a um grupo de mulheres, um evento descontextualizado. «A violência contra as mulheres é definida como universal e estrutural e fundamenta-se no sistema de dominação patriarcal presente em praticamente todas as sociedades do mundo ocidental» (PASINATO, 2011). Assim, reitera-se que a violência contra as mulheres é um fenômeno que pode ser observado em larga escala, transcendendo eras históricas.

\subsection{Feminicídio Tipificado}

A previsão do feminicídio como qualificadora de tipo penal, oficialmente, no ordenamento jurídico brasileiro, aconteceu no dia 8 de março de 2015, com a promulgação da Lei n. 13.104, que veio alterar o artigo 121 do Decreto-Lei n. 2.848. O artigo 121 trata do crime de homicídio. A alteração inclui um novo inciso em seu rol de tipificações qualificadas, que agora categoriza como específico o homicídio realizado "contra a mulher por razões da condição de sexo feminino" (BRASIL, 2015). Segundo a norma, esse requisito normativo pode se caracterizar em duas circunstâncias: quando o homicídio decorre de violência doméstica e familiar; e quando ocorre por menosprezo ou discriminação à condição de mulher.

A modalidade do feminicídio traz, ainda, hipóteses de aumento de pena:

$\S 7^{\circ}$ A pena do feminicídio é aumentada de $1 / 3$ (um terço) até a metade se o crime for praticado: 
I - durante a gestação ou nos 3 (três) meses posteriores ao parto;

II - contra pessoa menor de 14 (quatorze) anos, maior de 60 (sessenta) anos ou com deficiência;

III - na presença de descendente ou de ascendente da vítima (BRASIL, 2015).

Ao tratar da tipologia do feminicídio, Gebrim e Borges (2014) trazem os tipos em que o crime pode se apresentar, chamados: feminicídio íntimo, quando é cometido em ambiente doméstico (relacionamento entre o agressor e a vítima), não se limitando às relações oriundas do matrimônio, incluindo nessa categoria o feminicídio executado por conviventes, noivos, namorados e parceiros, ou mesmo membros da família, como pai, padrasto, irmão ou primo; e feminicídio não íntimo, em que a vítima não tem relação com seu agressor, aqui sendo inclusos os casos de morte provocada por clientes (em se tratando de trabalhadoras sexuais), por amigos, vizinhos ou desconhecidos, assim como a morte ocorrida no contexto do tráfico de pessoas, sempre tendo o motivo sexual como fundamental para sua qualificação como feminicídio (p. 62-62).

No Brasil, a medida é uma reação do Estado brasileiro à violência de gênero, como se explica:

O legislador penal baseou-se em dados estatísticos constantes no relatório da Comissão Parlamentar Mista de Inquérito da Violência contra a Mulher, de 2013, onde se constata que quarenta e três mil e setecentas mulheres foram assassinadas no Brasil entre os anos de 2000 e 2010, sendo que $41 \%$ delas foram mortas em suas residências, por pessoas com quem mantinham relações domésticas, de coabitação ou de afeto (MARQUES; GUIMARÃES, 2015). 
Ademais, lembra-se que, de acordo com a Lei 8.072, o homicídio qualificado configura crime hediondo, contra o qual incide o rigor penal. Dito de outra forma: tipificado o crime hediondo de feminicídio, estão caracterizadas as mortes de mulheres decorrentes de conflitos de gênero, ou seja, pelo fato de serem mulheres.

O feminicídio é um crime hediondo. O art. $2^{\circ}$ da Lei 13.104/15 alterou o artigo $1^{\circ}$ da Lei 8.072/90 (lei dos crimes hediondos) para incluir nesse rol o homicídio qualificado do inciso VI, do $\S 2^{\circ}$, do art. 121 do CP. Portanto, não há nenhuma dúvida de que o feminicídio (não o simples feminicídio: assassinato de uma mulher fora do contexto da violência de gênero) é um crime hediondo (BIANCHINI; GOMES, 2015).

Cabe observar que houve forte crítica à lei em razão de sua suposta falta de necessidade. Tais protestos buscam fundamento no princípio da legalidade, previsto do artigo $5^{\circ}$, inciso XXXIX da Constituição Federal, que dita que "não há crime sem lei anterior que o defina, nem pena sem prévia cominação legal” (BRASIL, 1988).

Esse, por sua vez, alia-se ao princípio da proporcionalidade, o qual postula que toda intervenção penal só se justifica se for necessária. Em outras palavras, toda medida restritiva de direitos deve ser a menos onerosa possível, sendo esta uma das principais características do direito penal brasileiro; a pena de prisão, por restringir a liberdade do indivíduo, somente pode ter incidência se absolutamente necessária (GOMES, 2004, p. 119).

Certos críticos da lei afirmam que ela não está em congruência com os princípios supracitados, relembrando que o homicídio executado em razão do gênero já se caracterizava como crime hediondo, qualificado por motivo torpe. Dessa forma, a nova modalidade de homicídio seria nada além de uma redundância jurídica, fruto de descuido do legislador. 
A rigor, o feminicídio já poderia (e, em alguns casos, já era) classificado como crime hediondo (homicídio por motivo torpe, fútil, etc.). Afinal, não há como negar torpeza na ação de matar uma mulher por discriminação de gênero (matar uma mulher porque usa minissaia ou porque não limpou corretamente a casa ou porque deixou queimar o feijão ou porque quer se separar ou porque depois de separada encontrou outro namorado, etc.). Mas esse entendimento não era uniforme. Daí a pertinência da nova lei, para dizer que todas essas situações configuram indiscutivelmente crime hediondo (BIANCHINI; GOMES, 2015).

Ainda que se verifique que o entendimento não era uniforme, há que se mencionar que era majoritário entre doutrina e jurisprudência, posto que a decisão monocrática que excluísse a hipótese qualificadora teria chances moderadas de ser reformada por órgão colegiado. Cita-se jurisprudência anotada por Delmanto et al. (2002), que exemplifica a inclusão do homicídio executado em razão de gênero na categoria de torpeza ao julgar que é motivo torpe "se mata por vingança a amante que o desprezou” (TJSP, RT 527/337; TJGO, RT 783/673 apud DELMANTO et al., 2002, p. 252).

\section{FUNÇÃO SIMBÓLICA DO FEMINICÍDIO}

O movimento feminista, maior defensor do endurecimento penal contra a prática feminicida, sustenta o seu apelo midiático como pilar mor para a defesa de sua efetivação no ordenamento jurídico nacional, buscando "no Direito Penal seu potencial simbólico, ou seja, a sua capacidade de tornar certas situações reconhecíveis como problemáticas” (BUENO, 2011, p. 88). 
Com efeito, observa-se, desde sua promulgação na data comemorativa do Dia Internacional da Mulher, o flagrante anseio por mero efeito simbólico da legislação em comento, aduzindo-lhe elementos político-sociais que chegam a ultrapassar a esfera criminal, expondo-os como motivações primordiais em favor do homicídio qualificado por feminicídio.

Examinam-se, a seguir, alguns exemplos da argumentação movimentada em favor da modalidade independente de feminicídio em meio às hipóteses qualificadoras de homicídio, compiladas por Gebrim e Borges (2014):

a) É argumentado que as circunstâncias em que o homicídio voltado contra a mulher por questões de gênero se dá em circunstâncias diversas do homicídio masculino, sendo necessário conhecê-las e expô-las ao público, de modo a motivar uma discussão sensível em torno da discriminação de gênero (GEBRIM; BORGES, 2014, p. 68). Essa expectativa se desdobra na racionalização a seguir:

Asseveram que, embora a persecução penal de quem tenha tirado a vida de uma mulher por razões de gênero possa ser alcançada pela norma jurídica neutra do homicídio, não é possível visualizar o contexto em que essas mortes têm lugar, tampouco o caráter social e generalizado da violência baseada no gênero, já que são registradas simplesmente como homicídios, tendentes a ser tratadas como assunto pessoal ou privado, resultantes de problemas passionais, cujos agressores são retratados como "loucos", "fora de controle" ou "animais", quando, na realidade, há um caráter profundamente social e político, resultado de relações de poder entre homens e mulheres na sociedade (GEBRIM; BORGES, 2014, p. 69).

Nesse sentido, cita-se, com efeito de analogia, uma observação feita por Netto e Borges (2013) sobre o antigo crime de atentado violento ao pudor mediante fraude, que apresentava a ressalva de que somente seria enquadrada no tipo a conduta realizada contra "mulher honesta”, trazendo para o Código Penal Brasileiro apreciação machista sobre o sujeito pas- 
sivo. Houve reforma do dispositivo, ainda que tardia, erradicando essa flagrante instância de discriminação contra a mulher da legislação vigente. Não obstante, Netto e Borges concluem que, “apesar dessas mudanças conceituais, a atitude em relação à sexualidade das mulheres ainda apresenta ranços machistas” (NETTO; BORGES, 2013, p. 329), ou seja, a lei se reformula, mas a sociedade continua ostentando os mesmos costumes, e a mulher ainda é objeto de discriminação social.

b) A tipificação obrigaria, ainda, segundo seus defensores, o Estado a criar políticas voltadas ao acolhimento da mulher em estágios anteriores de violência de gênero, visando a uma atenção especial no sentido do combate ao crime de feminicídio. Ademais, ela facilitaria o acesso à justiça por parte das mulheres vítimas de violência de gênero e contribuiria para uma revitalização da prática magistral, que ainda seria demasiado dogmática, inconsistente com os anseios sociais postos em xeque com a violação de bens jurídicos tutelados pelo direito penal (GEBRIM; BORGES, 2014, p. 68-69).

Diante do exposto no segundo tópico do trabalho, a aspiração descrita nesse argumento decorre justamente da ilusão própria do direito penal simbólico. Anjos relata a experiência posterior à promulgação de tantas outras leis que aspiravam ao controle da atividade criminal:

Não obstante tais leis visassem ao combate do crime, elas não conseguiram diminuir a criminalidade. Na verdade, o único resultado prático destas leis foi abarrotar ainda mais os presídios, sem solucionar as múltiplas causas estruturais que geram as diversas modalidades de delitos (2007).

Isso porque o aparato estatal para a resposta ao crime, no caso a lei penal simbólica, se limita à promulgação da norma, ao mesmo tempo em que as esferas judicial e executiva permanecem despreparadas para lidar com o ajuste penal. 
Outrossim, trata-se de um caminho inverso do direito penal mínimo: iniciar a tutela de um bem jurídico na esfera criminal, esperando-se que ela passe, então, a ser amparada pelas demais instâncias jurídicas.

c) Ademais, sugerem que a criminalização do feminicídio incitaria e facilitaria o acesso à justiça por parte das mulheres vítimas de violência de gênero e contribuiria para uma revitalização da prática magistral, que, segundo os defensores da tipificação, ainda seria demasiado dogmática, inconsistente com os anseios sociais postos em xeque com a violação de bens jurídicos tutelados pelo direito penal (GEBRIM; BORGES, 2014, p. 69).

d) Chegam mesmo a afirmar que o assassinato de uma mulher em virtude de sua condição de mulher deveria afastar o princípio da mínima intervenção do direito penal que norteia o estudo e aplicação das normas penais no Brasil, defendendo a tutela penal de direitos pleiteados por minorias de raça, gênero, religião, dentre outras (GEBRIM; BORGES, 2014, p. 69).

O estudo das ciências de repressão do crime, contudo, possui ressalvas para com tal posicionamento, pois a intervenção penal mínima é consagrada na legislação penal nacional, precisamente porque há sempre uma tendência a punir mais. No mesmo sentido, lembra-se que no processo de persecução penal figuram o aparato repressor estatal e o acusado - assim, no direito penal, o polo hipossuficiente é o acusado, não a vítima:

[...] o paradigma do direito penal mínimo assume como única justificação do direito penal o seu papel de lei do mais fraco em contrapartida à lei do mais forte, que vigoraria na sua ausência; portanto, não genericamente a defesa social, mas sim a defesa do mais fraco, que no momento do delito é a parte ofendida, no momento do processo é o acusado e, por fim, no momento da execução, é o réu (FERRAJOLI, 2002, p. 32).

Por conseguinte, é claramente manifesta a intenção prioritariamente simbólica por trás da norma, mesmo porque 
os movimentos feministas alegam que não estão particularmente interessados na punição dos agressores, mas, com maior ênfase, buscam o Direito Penal como meio declaratório de que os comportamentos violentos que vitimam as mulheres são tão importantes quanto aqueles referentes aos homens [...] (BUENO, 2011, p. 88).

Outrossim, conforme foi anteriormente constatado, a Lei n. 13.104/2015 tem por base o relatório da Comissão Parlamentar Mista de Inquérito da Violência contra a Mulher. Desse modo, está presente a apreciação da realidade social a que deve atender a lei penal. Como visto, ao alcance da função instrumental do direito penal é imprescindível a submissão do projeto de alteração legal ao escrutínio da política criminal de Liszt. $\mathrm{Na}$ realidade, a análise dos fatos (que reclamam tutela penal) ignoraram a fundamental observação da legislação penal e demais aspectos de prática forense essenciais à política criminal; isso porque, como acusam Marques e Guimarães, a decisão não passou pelo escopo dessa ciência:

O feminicídio enquadra-se perfeitamente no conceito de Direito Penal Simbólico, uma vez que se trata de criminalização de uma conduta originada sem um estudo Político-Criminal, justificada apenas em dados estatísticos de violência contra a mulher, visando, de maneira clara, instituir tranqüilidade na população e transparecer que o legislador está cumprindo com seu dever (2015).

Nesses termos, nota-se que a maior motivação para a promulgação da lei tinha cunho de simbologia feminista, sem passar pelo filtro da política criminal. Assim, a repressão do delito torna-se meramente incidental ante o real objetivo da norma: a efetuação do poder simbólico sobre a sociedade. 


\section{CONSIDERAÇÕES FINAIS}

O movimento feminista promove, desse seu nascimento no Brasil, uma luta para trazer o princípio de equidade de gêneros para o ordenamento jurídico, uma vez que o androcentrismo possibilitou a discriminação das mulheres nas diversas camadas da sociedade ocidental por toda sua evolução histórica.

Essa luta abrange o estabelecimento de elementos simbólicos do feminismo em diferentes esferas do direito, justificável por seus defensores por buscar dialogar com a sociedade por meio do ordenamento jurídico, não configurando o direito penal exceção, embora esse ramo jurídico tenha um conjunto principiológico contrário a tal abordagem. A tipificação do feminicídio como qualificadora é uma dessas instâncias de uso simbólico para o alcance de um ideal feminista, utilizando a pena como um meio de veiculação de sua retórica, esperando causar efeito social no sentido de reprimir a violência em razão de gênero.

O direito penal, entretanto, não deve aceitar em seu âmago medidas simbólicas, uma vez que seu caráter garantista o reveste de princípios designados à limitação do poder punitivo do estado e ao alcance do seu fim (repressão do crime) com o menor custo social possível, o que, quando se trata do cerceamento de direitos, se traduz na menor ingerência da atuação penal. É incompatível com os objetivos e princípios do direito penal de um Estado Democrático de Direito, o endurecimento de pena aplicada a um indivíduo com exclusiva intenção de exercer força midiática na sociedade.

Não se trata de negligenciar a inequívoca violência contra as mulheres, universalmente perceptível, ou tampouco negar-lhe resposta estatal, menosprezando a opressão feminina sob a ótica androcêntrica. Com efeito, o caso que se defende é pela atenção estatal à violência sofrida em razão de gênero, uma vez que uma lei penal que objetive tão somente disfarçar a realidade da resposta do Estado a esse crime, naturalmente não deve ser 
aceita em nosso ordenamento jurídico. Ainda que deficitária, é o primeiro passo na busca da proteção estatal. Há muito a ser efetivado, porém as primeiras tratativas são evidentes.

A violência contra a mulher urge eficiência no campo penal, alcançável por meio de leis cuja primeira função seja legitimar a ordem, e não simples aparente eficiência, pois não é a aparência de segurança que manterá a mulher segura.

\section{REFERÊNCIAS}

ANJOS, Fernando Venice dos. Direito penal simbólico e finalidade da pena. Boletim do IBCCRIM, n. 171, fev. 2007. Disponível em <http://www.ibccrim. org.br/novo/boletim_artigo/3369_Direito_penal_simbolico_e_sinalidade_da pena> Acesso em: 5 out. 2015.

BARATTA, Alessandro. Princípios do direito penal mínimo para uma teoria dos direitos humanos como objeto e limite da lei penal. Tradução Francisco Bissoli Filho. Revista Doutrina Penal, Buenos Aires: Depalma, n. 10-40, 1987. Disponível em: <http://danielafeli.dominiotemporario.com/doc/ALESSANDRO\%20BARATTA\%20Principios\%20de\%20direito\%20penal\%20minimo.pdf>.

BIANCHINI, Aline; GOMES, Luiz Flávio. Feminicídio: entenda as questões controvertidas da Lei 13.104/2015. Disponível em: <http://professorlfg.jusbrasil.com.br/artigos/173139525/feminicidio-entenda-as-questoes-controvertidas-da-lei-13104-2015>. Acesso em: 2 out. 2015.

BIJOS, Leila. Violência de gênero: crimes contra a mulher. Contexto e Educação, Ijuí: Ed. Unijuí, n. 71/72, jan./dez. 2004. Disponível em: <https://www. revistas.unijui.edu.br/index.php/contextoeducacao/article/view/1136/891>. Acesso em: 18 out. 2015.

BITENCOURT, Cezar Roberto. Tratado de direito penal: parte geral. 17. ed. São Paulo: Saraiva, 2012. V. 1.

BOURDIEU, Pierre. A dominação masculina. Tradução Maria Helena Kühner. 2. ed. Rio de Janeiro: Bertrand Brasil, 2002. 
. O poder simbólico. Tradução Fernando Tomaz. Rio de Janeiro: Bertrand Brasil, 1989.

BRASIL. Constituição Federal. 1988. . Lei $n^{-}$13.104. 2015.

BUENO, Mariana Guimarães Rocha da Cunha. Feminismo e direito penal. São Paulo: USP, 2011. 180 f. Dissertação (Mestrado em Direito Penal) - Programa de Mestrado em Direito Penal, Faculdade de Direito, Universidade de São Paulo, 2011.

CAPEZ, Fernando. Curso de direito penal: parte geral. 15. ed. São Paulo: Saraiva, 2011. V. 1.

CHAVES JUNIOR, Airto. O controle penal dos excedentes: as funções simbólicas do direito penal e a eficácia invertida quanto seus objetivos declarados. Revista de la Facultad de Derecho y Ciencias Politicas, Medellín: Universidad Pontificia Bolivariana, v. 41, n. 114, jan. 2011. Disponível em: <http://www.scielo.org.co/scielo.php?script=sci_arttext\&pid= S0120$38862011000100003 \& \operatorname{lng}=$ pt\&nrm=iso $>$. Acesso em: 9 out. 2015.

DELMANTO, Celso et al. Código penal comentado. 6. ed. Rio de Janeiro: Renovar, 2002.

DELMAS-MARTY. Mireille. Os grandes Sistemas de Política Criminal. Editora Manole, 2004.

FERRAJOLI, Luigi. A pena em uma sociedade democrática. In: Discursos Sediciosos: Crime, Direito e Sociedade, Rio de Janeiro: Revan, ano 7, n. 12, 2002.

GEBRIM, Luciana Maibashi; BORGES, Paulo César Corrêa. Violência de gênero: tipificar ou não o femicídio/feminicídio? Revista de Informação Legislativa, Brasília, a. 51, n. 202, abr./jun. 2014. Disponível em: <http:// www2.senado.leg.br/bdsf/bitstream/handle/id/503037/001011302. pdf?sequence=1>. Acesso em: 4 jun. 2015 .

GOMES, Luiz Flávio. Direito penal: parte geral. São Paulo: Revista dos Tribunais, 2004. V. 1. 
Mídia, segurança pública e justiça criminal. Revista Jus Navigandi, Teresina, ano 12, n. 1.628, 16 dez. 2007. Disponível em: <http://jus.com.br/ artigos/10768>. Acesso em: 5 out. 2015.

KERSTENETZKY, Maíra Souto Maior. Direito penal simbólico: criação de leis mais rigorosas diante do clamor social e midiático. 2012. Disponível em: <http://www.ambitojuridico.com.br/site/?n_link=revista_artigos_ leitura\&artigo_id=12216>. Acesso em: 5 out. 2015.

LISZT, Franz Von. Tratado de direito penal alemão. Tradução José Hygino Duarte Pereira. Rio de Janeiro: F. BRIGUIET \& C., 1899.

MARQUES, Daniel Wollz; GUIMARÃES, Isaac Sabbá. Política criminal: o feminicídio e o direito penal simbólico. Disponível em: $<\mathrm{http}$ ://danewmarques. jusbrasil.com.br/artigos/240740977/politica-criminal-o-feminicidio-e-o-direito-penal-simbolico?ref=topic_feed> Acesso em: 18 out. 2015.

NETTO, Helena Henkin Coelho; BORGES, Paulo César Corrêa. A mulher e o direito penal brasileiro: entre a criminalização pelo gênero e a ausência de tutela penal justificada pelo machismo. Revista de Estudos Jurídicos Unesp, Franca, a. 17, n. 25, 2013. Disponível em: <http://seer.franca.unesp.br/index. php/estudosjuridicosunesp/article/viewFile/927/917>. Acesso em: 27 set. 2015.

PASINATO, Wânia. "Femicídios" e as mortes de mulheres no Brasil. 2011. Disponível em: <http://www.scielo.br/pdf/cpa/n37/a08n37.pdf $>$. Acesso em: 2 out. 2015.

PRADO, Luiz Regis. Curso de direito penal brasileiro. 9. ed. São Paulo: Revista dos Tribunais, 2010.

SANTOS, Juarez Cirino dos. Política criminal: realidades e ilusões do Discurso Pena. In: Discursos Sediciosos: Crime, Direito e Sociedade, Rio de Janeiro: Revan, ano 7, n. 12, 2002. 